\title{
Meningoencefalite e encefalomalacia por Herpesvírus bovino-5: distribuição das lesões no sistema nervoso central de bovinos naturalmente infectados ${ }^{1}$
}

\author{
Fabiana Elias², Ana Lucia Schild ${ }^{3}$ e Franklin Riet-Correa ${ }^{4}$
}

\begin{abstract}
Elias F., Schild A. L. \& Riet-Correa F. 2004. [Bovine herpesvirus type-5 meningoencephalitis and malacia: histological lesions distribution in the central nervous system of naturally infected cattle.] Meningoencefalite e encefalomalacia por Herpesvírus bovino-5: distribuição das lesões no sistema nervoso central de bovinos naturalmente infectados. Pesquisa Veterinária Brasileira 24(3):123-131. Laboratório Regional de Diagnóstico, Faculdade de Veterinária, UFPel, Cx. Postal 354, Pelotas, RS 96010-900, Brazil. E-mail: alschild@ terra.com.br

The distribution of the histological lesions in the central nervous system (CNS) of cattle naturally infected by bovine herpes virus type-5 (BHV-5) was determined in 12 affected calves from 10 outbreaks of the disease diagnosed by the Regional Diagnostic Laboratory (LRD) at Pelotas University, from 1986 to 2003. The epidemiological data, clinical signs and duration of clinical course were obtained from the files of LRD. Transversal sections were performed at different levels in 10\% formalin-fixed CNS. The sections were made in the frontal, parietal, temporal e occipital lobes of thetelencephalic hemispheres, basal ganglia and internal capsule, thalamus, anterior colliculus, pons, cerebellar peduncles, cerebellum, medulla oblongata and cervical spinal cord. Paraffin embedded tissues were sectioned and stained with hematoxylin and eosin. The severity and distribution of the inflammatory and malacic lesions were evaluated in all sections. These lesions were related with the epidemiological and clinical aspects of the disease. The outbreaks of the disease were observed in different seasons of the year. Affected animals were 2 to 24-month-old, of different breeds and both sexes. Gross lesions characterized by yellow and depressed areas in the cerebral cortex were observed in five calves. In two of them, similar lesions were additionally observed in thalamus, basal nuclei, and internal capsule. Congestion and multifocal hemorrhages were observed in most cases. The histological lesions were characterized by non-suppurative meningoencephalitis in all sections of CNS, but more severe in the frontal cortex. Focal or widespread malacia with infiltration of Gitter cells were observed in all sections of cerebral cortex, basal ganglia, internal capsule, and thalamus. In some cases mild malacia was also observed in the rostral colliculi, pons, medulla, cerebellum and cervical spinal cord. Intranuclear inclusion bodies were seen in all cases studied; they were frequent in regions of the cerebral cortex near mild to moderate inflammatory or malacic lesions. In two cases the inclusion bodies were also seen in the basal ganglia and thalamus. The severity of the histological lesions was not proportional with the clinical course of the disease. The presence of lesions of malacia in different regions of the CNS, an aspect not mentioned in most reports of BHV-5 infections, could be due to variable pathogenicity of different virus isolates. Alternatively, it is possible that BHV-5 encephalitis occurs due to the reactivation of the virus in cattle previously affected by polioencefalomacia; this last sequence of events was already demonstrated experimentally by our research group.
\end{abstract}

INDEX TERMS: Bovine herpesvirus type-5, BHV-5, cattle, meningoencephalitis, polioencephalomalacia.

${ }^{1}$ Recebido em 29 de março de 2004.

Aceito para publicação em 20 de abril de 2004.

Trabalho financiado pelo CNPq - Programa de Apoio a Grupos de Excelência (Pronex 661069/1997).

${ }^{2}$ Aluna do Curso de Pós-Graduação, Laboratório Regional de Diagnóstico, Universidade Federal de Pelotas (UFPel), Pelotas, RS.

\footnotetext{
${ }^{3}$ Laboratório Regional de Diagnóstico, Faculdade de Veterinária, UFPel, Campus Universitário s/n, Pelotas, RS 96010-900. *Autor para correspondência. E-mail: alschild@ terra.com.br

${ }^{4}$ Centro de Saúde e Tecnologia Rural, Universidade Federal de Campina Grande (UFCG), Campus de Patos, 58700-000 Patos, PB.
} 
RESUMO.- Para determinar a distribuição das lesões histológicas que ocorrem no sistema nervoso central (SNC) de bovinos naturalmente infectados por herpesvírus bovino-5 (BHV-5) foram estudados 12 bovinos provenientes de 10 surtos da enfermidade diagnosticados pelo Laboratório Regional de Diagnóstico (LRD) da Faculdade de Veterinária da UFPel, entre 1986 e 2003. A epidemiologia, história clínica e evolução da enfermidade foram obtidas dos arquivos do LRD. Cortes do SNC foram realizados nos materiais conservados em formalina $10 \%$ abrangendo as regiões frontal, parietal, temporal e occipital do córtex telencefálico, cápsula interna e núcleos da base, tálamo, colículo rostral, ponte, pedúnculos cerebelares, cerebelo, bulbo na altura do óbex emedula cervical. As secções foram processadas rotineiramente e coradas por hematoxilina e eosina. Foram avaliadas a distribuição e intensidade das lesões inflamatórias e de malacia, que foram relacionadas com os aspectos epidemiológicos e clínicos da doença. Surtos da enfermidade foram observados em todas as estações ano. Foram afetados bovinos de 2 a 24 meses, de diferentes raças e de ambos os sexos. Macroscopicamente, foram observadas áreas amareladas e deprimidas no córtex telencefálico de cinco bovinos necropsiados. Adicionalmente, essas lesões foram observadas no tálamo, núcleos da base e cápsula interna de dois bovinos. Congestão e hemorragias multifocais foram observadas na maioria dos casos. Em todos os bovinos estudados a lesão histológica caracterizou-se por meningoencefalite não-supurativa observada em todas os cortes, porém mais acentuada no córtex frontal. Áreas de malacia focal ou difusa com presença de células "Gitter" foram observadas em todas as regiões do córtex cerebral e nos núcleos da base, cápsula interna e tálamo. Em alguns casos, lesões discretas de malacia foram observadas no colículo rostral, ponte, bulbo, cerebelo e medula cervical. Corpúsculos de inclusão intranucleares foram encontrados em todos os casos estudados nas diferentes regiões do córtex cerebral, preferentemente em áreas que apresentavam lesões inflamatórias e de malacia discretas a moderadas. Em dois casos estes corpúsculos foram observados, também, nos núcleos da base e tálamo. Foi observado que a intensidade das lesões histológicas não é proporcional ao curso clínico da enfermidade. A presença de lesões de malacia em diferentes regiões do SNC, aspecto não mencionado na maioria dos trabalhos anteriores sobre a doença, pode ser devida a variações na patogenicidade das cepas virais envolvidas. Outra possibilidade équea encefal ite tenha ocorrido em consequêencia da reativação do BHV-5 em animais afetados por polioencefalomalacia. Essa seqüência de eventos já foi demonstrada previamente em experimentos realizados pelo grupo de pesquisa dos autores.

TERMOS DE INDEXAÇÃO: Herpesvírus bovino-5, BHV-5, bovinos, meningoencefalite, polioencefalomalacia.

\section{INTRODUÇÃO}

Meningoencefalite por herpesvírus bovino-5 (BHV-5), freqüentemente observada no Rio Grande do Sul, é uma enfermidade do sistema nervoso central (SNC) que se caracteriza histologicamente por meningoencefalite não-supurativa e necrose do córtex cerebral (Hall et al. 1966, Riet-Correa et al. 1989, Weiblen et al. 1989, Schild et al. 1994, Riet-Correa \& Schild 1995). De 1978 a 2003, de um total de 4.407 bovinos cujos tecidos foram examinados pelo
Laboratórrio Regional de Diagnóstico (LRD), 417 ( 10\%) apresentavam histórico de sinais clínicos de distúrbios nervosos. Desses, $12(2,87 \%$ foram diagnosticados como encefalite por BHV-5.

A meningoencefalite por BHV-5 é epidemiológica e clinicamente semelhante à polioencefalomalacia (PEM), condição de ruminantes, caracterizada por necrose cerebrocortical atribuída a distúrbios no metabolismo da tiamina, mas que ocorre, também, associada a vários outros fatores, como na intoxicação por cloreto de sódio/síndrome de privação de água, envenenamento por chumbo (Lemos \& Nakasato 2001) e altos níveis de $\mathrm{H}_{2} \mathrm{~S}$ intra-ruminal causados por excesso de enxofre na dieta (Lorenagan et al. 1998). Essa condição tem sido descrita em ruminantes em diversos estados do Brasil, incluindo o Rio Grande do Sul (Riet-Correa et al. 1983, Santos et al. 1983, Colodel et al. 1998, Nakasato et al. 2000). Quando se investigou a possível relação entre PEM e encefalite por BHV-5 (Hübner et al. 1999, David 2002) foi observado que em bovinos previamente inoculados com BHV-5, a indução de PEM através da administração de amprólio ou enxofre, a provocou lesões histológicas de malacia da substância cinzenta nos núcleos da base, tálamo, corpo geniculado e colículos rostral e caudal. Nesses relatos menciona-se a necessidade de um estudo detalhado do tipo e distribuição das lesões no SNC de bovinos afetados por essa encefalite viral, sugerindo que as lesões de PEM poderiam ser responsáveis pela reativação do vírus latente no SNC dos bovinos.

Lesões macroscópicas no sistema nervoso central nem sempre ocorrem na meningoencefalite por BHV-5 (Barenfus et al. 1963, Hall et al. 1966, Riet-Correa et al. 1989, Ely et al. 1996). Quando ocorrem, o córtex cerebral pode apresentar áreas de coloração amarelada ou acinzentada. Ocasionalmente, essas áreas apresentam-se deprimidas podendo observar-se cavitação da substância cinzenta (Riet-Correa \& Schild 1995, Salvador et al. 1998). Congestão das meninges, petéquias e edema no cérebro e cerebelo foram descritos em animais de 1 a 4 meses (Dias et al. 1982). Malacia, caracterizada por áreas deprimidas de 1 a $2 \mathrm{~cm}$ de diâmetro, de coloração amarelada ou avermelhada, no córtex cerebral é descrita por Salvador et al. (1998). Riet-Correa et al. (1996) observaram achatamento das circunvoluções cerebrais, protusão do cerebelo através do forâmen magno e congestão das meninges. Em surtos observados no Mato Grosso foram descritos congestão encefálica difusa, hemorragias submeningeanas multifocais, achatamento de circunvoluções cerebrais e áreas de malacia (Colodel et al. 2002).

A lesão histológica da infecção por BHV-5 é descrita como meningoencefalite não-supurativa com necrose do córtex cerebral (Hall et al. 1966, Riet-Correa et al. 1989, Ely et al. 1996, Riet-Correa et al. 1996, Salvador et al. 1998, Colodel et al. 2002, Perez et al. 2003). Outros autores mencionam meningoencefalite não supurativa com degeneração e necrose neuronal (Barenfus et al. 1963, D'Offay et al. 1993), ou com degeneração do córtex cerebral, vacuolização ao redor deneurônios eáreas focais denecrose (Bagust $\&$ Clarck 1972). De modo geral, é descrita a presença de manguitos perivasculares com variado número de camadas de células mononucleares nas meninges e em diversas áreas do SNC, gliose focal ou difusa, satelitose eneuronofagia, e edema perivascular e perineuronal (Johnston et al. 1962, Riet-Correa et al. 1989, RietCorrea \& Schild 1995, Ely et al. 1996). Mieliteé, também, relatada 
(Johnston et al. 1962, Hall et al. 1966). Corpúsculos de inclusão intranucleares são encontrados em astrócitos e neurônios (Johnston et al. 1962, Gardiner \& Nairn 1964, Weiblen et al. 1989, Riet-Correa et al. 1989, D'Offay et al. 1993, Ely et al. 1996, Salvador et al. 1998, Sanches et al. 2000, Colodel et al. 2002).

As lesões inflamatórias podem variar de moderadas a acentuadas e são mais marcadas no córtex, mas ocorrem, também, na cápsula interna, no tálamo e nos colículos (Gardiner \& Nairn 1964, Eugster et al. 1974). Discretas alterações são observadas no cerebelo, pedúnculos cerebelares, ponte e medula oblonga (Johnston et al. 1962, Gardiner \& Nairn 1964, Riet-Correa et al. 1989).

Degeneração e necrose neuronal ou extensas áreas de malacia associadas a células "Gitter" são descritas freqüentemente no córtex cerebral (Dias et al. 1982, Riet-Correa et al. 1989, Ely et al. 1996, Salvador et al. 1998, Perez et al. 2003).

Os objetivos deste trabalho foram descrever qualitativa e quantitativamente as lesões histológicas do cérebro de bovinos necropsiados em 10 surtos de meningoencefalite causada por BHV-5, ocorridos na área de influência do LRD, determinando a sua distribuição nas diferentes áreas do SNC e relacionando-as com os aspectos clínicos e epidemiológicos da doença.

\section{MATERIAL E MÉTODOS}

Para o estudo e mapeamento das lesões histológicas observadas no SNC de bovinos com diagnóstico de encefalite por herpesvírus bovino5 foi estudado o SNC de 12 animais provenientes de 10 surtos diagnosticados pelo Laboratório Regional de Diagnóstico (LRD) da Faculdade de Veterinária, Universidade Federal de Pelotas (UFPel). Os dados epidemiológicos e a história clínica dos animais em cada surto foram obtidos por revisão dos arquivos do LRD. O protocolo de cultivo viral foi realizado no Laboratório de Virologia da Faculdade de Veterinária da UFPel. Nos Surtos 2, 3, 6, 8 e 9 o diagnóstico foi realizado por isolamento do vírus em cultivos celulares. Nos Surtos 1, 4, 5, 7 e 10 o cultivo viral não foi realizado, e o diagnóstico foi feito com base nos dados epidemiológicos, sinais clínicos, lesões macroscópicas e histológicas, incluindo a observação de corpúsculos de inclusão intranucleares em astrócitos ou neurônios.

Os cortes do SNC foram realizados abrangendo as seguintes regiões: núcleos da base e cápsula interna, tálamo, colículo rostral, ponte, bulbo na altura do óbex, cerebelo, pedúnculos cerebelares, medula cervical e as regiões frontal, parietal, temporal e occipital do córtex telencefálico. Todas as secções foram processadas rotineiramente e coradas pela técnica de hematoxilina-eosina (HE). Em cada secção, as lesões de malacia foram avaliadas quantitativa e qualitativamente atribuindo-se aos mesmos três diferentes graus: (1) lesão discreta, caracterizada pela presença focal ou multifocal de necrose neuronal, com edema perineuronal e perivascular e presença de pequeno número de macrófagos e/ou nódulos gliais ao redor dos neurônios necróticos; (2) lesão moderada, caracterizada pela presença multifocal ou difusa de necrose neuronal com edema perineuronal e perivascular, satelitose e neuronofagia e presença de nódulos multifocais de macrófagos, linfócitos e células da glia; (3) lesão grave, caracterizada por áreas multifocais ou difusas de malacia afetando a substância branca e cinzenta com substituição do tecido nervoso por células "Gitter". As lesões inflamatórias foram classificadas, também, em discretas, moderadas ou graves de acordo com o número aproximado de camadas de células inflamatórias que formavam os manguitos perivasculares e a quantidade de manguitos em cada secção. Os dados foram analisados e relacionados com a epidemiologia e o quadro clínico dos surtos.

\section{RESULTADOS}

\section{Epidemiologia e sinais clínicos}

Os surtos da enfermidade foram observados em todas as estações do ano e a idade dos bovinos afetados variou de 2 a 24 meses. Foram afetados bovinos de ambos os sexos e de diferentes raças. Em cinco ocasiões (Surtos 2-4, 7 e 9) os bovinos eram da raça Hereford ou suas cruzas, e em um (Surto 10) eram Red Angus; em quatro (Surtos 1, 5, 6 e8)eram bovinos de cruzas de diferentes raças de corte. Em uma propriedade (Surto 5) a doença ocorreu em apenas um bovino. Em sete surtos (2, 3, 6-10) havia o histórico

\section{Quadro 1. Epidemiologia dos surtos de meningoencefalite por herpesvírus bovino 5 (BHV-5) em bovinos} diagnosticados na área de influência do LRD, UFPel, entre 1986 e 2003

\begin{tabular}{|c|c|c|c|c|c|c|c|c|c|}
\hline $\begin{array}{l}\text { Surto/ Bo- } \\
\text { vino no }\end{array}$ & Município & Mês/ano & $\begin{array}{l}\text { Idade } \\
\text { (meses) }\end{array}$ & $\begin{array}{l}\text { Manejo (fato- } \\
\text { res de estresse) }\end{array}$ & Forma de criação & $\begin{array}{l}\text { Evolução } \\
\text { (dias) }\end{array}$ & $\begin{array}{l}\text { Total de } \\
\text { animais }\end{array}$ & $\begin{array}{c}\text { Morbidade } \\
\text { no }(\%)\end{array}$ & $\begin{array}{l}\text { Letalidade } \\
\text { no }(\%)\end{array}$ \\
\hline $1 / 1.1$ & $\begin{array}{l}\text { Capão } \\
\text { do Leão }\end{array}$ & $12 / 86$ & 24 & - & A campo & 15 & 150 & $3(2)$ & $3(100)$ \\
\hline $2 / 2.1$ & $\begin{array}{l}\text { Sta. Vitória } \\
\text { do Palmar }\end{array}$ & $07 / 93$ & 18 & Transporte & A campo & $3-4$ & 237 & $9(3,80)$ & $9(100)$ \\
\hline $3 / 3.1$ & Sta. Vitória & $\begin{array}{c}\text { 05/94 } \\
\text { do Palmar }\end{array}$ & $7-8$ & $\begin{array}{c}\text { Desmame, vacinação } \\
\text { e assinalação }\end{array}$ & A campo & $2-3$ & 406 & $27(6,65)$ & $21(77,8)$ \\
\hline $4 / 4.1$ & $\begin{array}{l}\text { Sta. Vitória } \\
\text { do Palmar }\end{array}$ & $09 / 95$ & 18 & $N C^{a}$ & $\begin{array}{l}\text { A campo (pastagem } \\
\text { de azevém e trevo) }\end{array}$ & $2-7$ & 56 & $14(25)$ & $14(100)$ \\
\hline $5 / 5.1$ & Rio Grande & $04 / 96$ & 18 & NC & A campo & 3 & 130 & $1(0,76)$ & $1(100)$ \\
\hline $6 / 6.1$ & Canguçu & 07/99 & 10 & Troca de alimentação & Confinados (silagem) NC & 300 & $4(1,33)$ & $1(25)$ & \\
\hline $7 / 7.1,7.2$ & Canguçu & $12 / 99$ & 2 & Desmame & A campo & $7-10$ & 100 & $6(6)$ & $6(100)$ \\
\hline 8 / 8.1 & Piratini & $03 / 00$ & 5 & $\begin{array}{l}\text { Desmame, vacinação } \\
\text { e assinalação }\end{array}$ & A campo & $2-5$ & 500 & $7(1,4)$ & $7(100)$ \\
\hline $9 / 9.1,9.2$ & $\begin{array}{l}\text { Sta. Vitória } \\
\text { do Palmarb }\end{array}$ & $09 / 02$ & $10-12$ & $\begin{array}{l}\text { Desmame, vacinação } \\
\text { e castração }\end{array}$ & $\begin{array}{l}\text { A campo (suplementação } \\
\text { com ração comercial) }\end{array}$ & $4-5$ & 360 & $9(2,5)$ & $2(22,2)$ \\
\hline $10 / 10.1$ & Herval & $10 / 03$ & 10 & $\begin{array}{l}\text { Transporte, troca } \\
\text { de potreiro }\end{array}$ & A campo & 14 & 87 & $4(4,59)$ & $3(75)$ \\
\hline
\end{tabular}

\footnotetext{
a Não consta.
}

bFoi observada acentuada variação nas condições climáticas na região, quando surgiram os primeiros sinais clínicos da enfermidade. 
de alguma prática de manejo como desmame, castração, vacinação, assinalação, transporte, dosificação ou troca de alimentação, realizada de 3 a 14 dias antes dos primeiros sinais clínicos. No Surto 9, após o desmame, os bovinos estavam sendo suplementados com ração comercial e também ocorreu acentuada variação nas condições climáticas no período em que ocorreram as mortes; no Surto 10 existia o histórico de troca de potreiro. No Surto 6 os bovino foram desmamados aos 10 meses e estavam confinados, recebendo silagem de sorgo e girassol e sal mineral. No Surto 7 os bezerros foram desmamados aos 2 meses de idade, estavam a campo e recebiam substituto de leite. Em quatro surtos $(3,6,9$ e 10) houve relato de remissão dos sinais clínicos e recuperação de alguns bovinos. O resumo dos dados epidemiológicose de morbidade e letalidade é apresentado no Quadro 1.

Os sinais clínicos caracterizaram-se por febre, tremores musculares, incoordenação, andar em círculos, pressão da cabeça contra objetos, marcha para trás, bruxismo, depressão ou agressividade, sialorréia, desidratação, cegueira, decúbito lateral com opistótono e dispnéia. A duração do curso clínico foi de 2 a 15 dias. Nos bovinos que sobreviveram por mais de 7 dias observou-se emagrecimento progressivo.

\section{Patologia}

Em 5 de 12 bovinos necropsiados, nos diferentes surtos diagnosticados de menigoencefalite por BHV-5, foram observadas lesões macroscópicas. Bovino 1.1 apresentava, na substância cinzenta do córtex cerebral, áreas marrons ou amareladas e deprimidas e no tálamo, núcleos de base e cápsula interna, cavidades de até $2 \mathrm{~mm}$ de diâmetro contendo líquido. Bovino 3.1 apresentava áreas achatadas e amareladas de 0,5 a $3 \mathrm{~cm}$ de diâmetro no córtex temporal em áreas próximas à cápsula interna, no tálamo, ventrículo lateral e no córtex occipital. Achatamento das circunvoluções, que estavam amolecidas e apresentavam pequenas áreas esbranquiçadas no córtex frontal foram observados no Bovino 7.1. Outro animal (Bov. 9.1) apresentava congestão cerebral, discretas áreas acinzentadas ou amareladas e deprimidas, no córtex occipital e temporal, congestão e hemorragias multifocais na substância branca e cinzenta e nas meninges, distribuídas em to das as regiões do SNC. Congestão meníngea acentuada e áreas amareladas e deprimidas no córtex foram observadas no Bovino 10.1.

Em todos os casos estudados a lesão histológica caracterizou-se por meningoencefalite não-supurativa com malacia em diversas áreas do SNC. A distribuição dessas lesões pode ser observada nos Quadros 2 e 3. Gliose focal e/ou difusa foi observada principalmente próxima às áreas de infiltrado perivascular de células inflamatórias. Havia manguitos perivasculares com predominância de macrófagos. Focos inflamatórios com discreto número de neutrófilos foram observados em al guns casos, e infiltrado de eosinófilos foi observado no Bovino 9.2. Nas áreas de malacia, em alguns casos, o neurópilo estava substituído por acúmulo acentuado de células "Gitter" (Fig. 1). Foram observadas, também, áreas focais ou difusas de necrose neuronal, caracterizadas por presença de neurônios eosinofílicos e retraídos, satelitose, neuronofagia, discreto número de macrófagos, distensão dos espaços perivasculares e vacuolização do neurópilo (Fig. 2). Areas de malacia discreta com acúmulo focal de macrófagos foram também observadas em alguns casos (Fig. 3). Em dois animais (Bov. 4.1 e 10.1), manguitos perivasculares de macrófagos foram observados, tanto na substância branca como no córtex cerebelar. As áreas de malacia observadas na medula cervical de dois animais (Bov. 2.1 e 4.1) estavam restritas à substância branca. Congestão foi um achado constante em todos os casos e em todas as regiões do SNC estudadas. Hemorragias foram freqüentemente encontradas. Meningite ocorreu em todos os casos, mas não em to das as secções e sua intensidade era proporcional à gravidade das lesões inflamatórias. Corpúsculos de inclusão intranucleares eosinofílicos foram observados em todos os casos, principalmente nos astrócitos e eventualmente em neurônios (Fig. 4), nas áreas cuja intensidade da lesão era de discreta a moderada (Quadro 2). 0 material dos bovinos necropsiados nos Surtos 2 e 8 não pôde ser recupera-

Quadro 2. Distribuição e intensidade das lesões de malacia, presença de corpúsculos de inclusão intranucleares nas diferentes secções do sistema nervoso central (SNC) avaliadas, e presença ou não de lesões macroscópicas em 10 bovinos com meningoencefalite por BHV-5

\begin{tabular}{|c|c|c|c|c|c|c|c|c|c|c|c|c|c|}
\hline \multirow{2}{*}{$\begin{array}{l}\text { Surtoa / } \\
\text { Bovino no }\end{array}$} & \multicolumn{4}{|c|}{ Córtex ${ }^{b}$} & \multirow{2}{*}{$\begin{array}{l}\text { Núcleos } \\
\text { da base }\end{array}$} & \multicolumn{3}{|c|}{ Cápsula Tálamo Colículo } & \multirow{2}{*}{ Cerebelo } & \multirow{2}{*}{\multicolumn{2}{|c|}{ Ponte Bulbo }} & \multirow{2}{*}{\multicolumn{2}{|c|}{$\begin{array}{l}\text { Medula Lesões } \\
\text { cervical macro }\end{array}$}} \\
\hline & $\mathrm{F}$ & $P$ & $T$ & 0 & & interna & & rostral & & & & & \\
\hline $1 / 1.1$ & $+t^{c}$ & + & + & $+c i$ & +++ & +++ & +++ & - & - & - & - & - & sim \\
\hline $3 / 3.1$ & +++ & NE & +++ & +++ & +++ & +++ & +++ & - & - & - & - & NE & sim \\
\hline 4 / 4.1 & + & + & ++ & $++\mathrm{ci}$ & + & + & + & + & + & + & + & + & - \\
\hline $5 / 5.1$ & $++c i$ & ++ & + & ++ & + & + & + & - & - & - & - & - & - \\
\hline $6 / 6.1$ & $++\mathrm{ci}$ & ++ & + & ++ & + & + & + & - & - & - & - & - & - \\
\hline $7 / 7.1$ & +++ & ++ & + & $+\mathrm{ci}$ & ++ & ++ & + & - & - & + & - & + & sim \\
\hline $7 / 7.2$ & ++ & $+\mathrm{Ci}$ & $+\mathrm{ci}$ & + & + & + & ++ & - & - & + & - & NE & - \\
\hline $9 / 9.1$ & +++ & $++\mathrm{ci}$ & ++ & +++ & $++c i$ & ++ & $++\mathrm{ci}$ & + & - & - & - & + & sim \\
\hline $9 / 9.2$ & +++ & + & + & $+c i$ & $++c i$ & ++ & $+c i$ & - & - & - & - & - & - \\
\hline $10 / 10.1$ & +++ & +++ & $++\mathrm{ci}$ & ++ & + & + & + & + & - & + & - & + & sim \\
\hline
\end{tabular}

aNos Surtos 2 e 8 os bovinoss apresentaram lesões histológicas características de infecção por BHV-5, entretanto os materiais não estavam disponíveis para o estudo da distribuição dessas lesões.

${ }^{b} \mathrm{~F}=$ córtex frontal, $\mathrm{P}=$ córtex parietal, $\mathrm{T}=$ córtex temporal, $\mathrm{O}=$ córtex occipital, $\mathrm{ci}=$ corpúsculo de inclusão, $\mathrm{NE}=$ não examinado, lesões macro $=$ lesões macroscópicas

c+ Malacia focal discreta, ++ multifocal moderada, com células "Gitter", + + + acentuada,com células "Gitter", - ausente. 

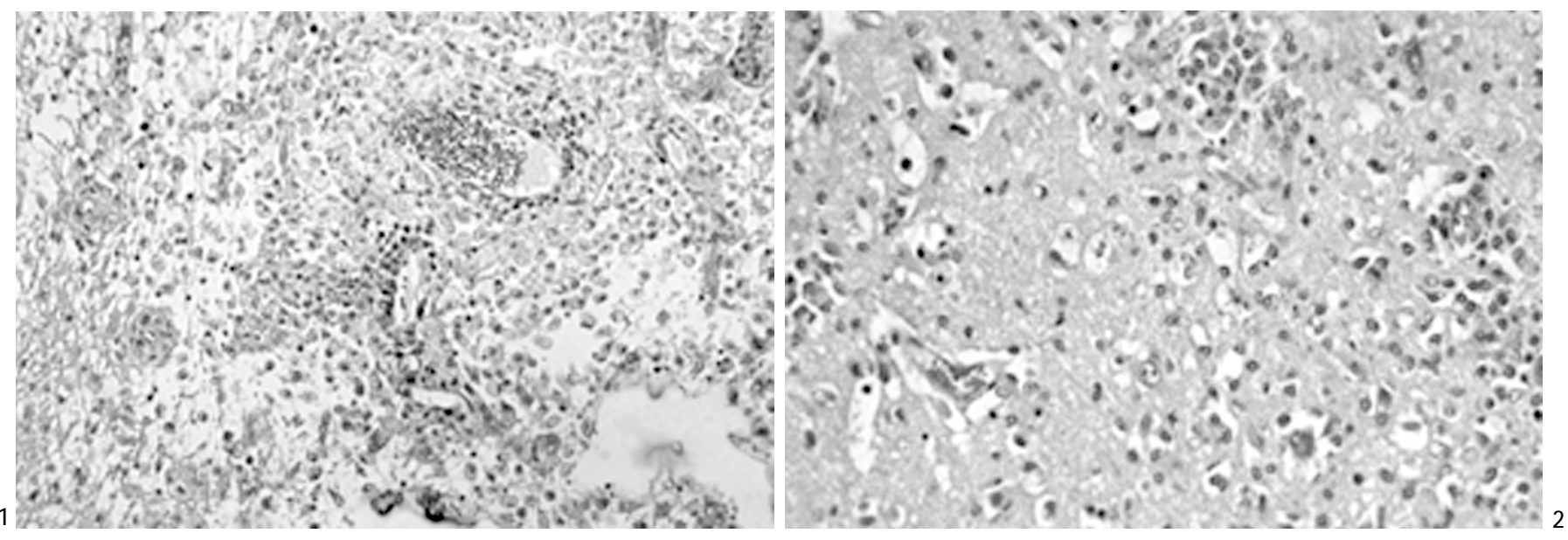

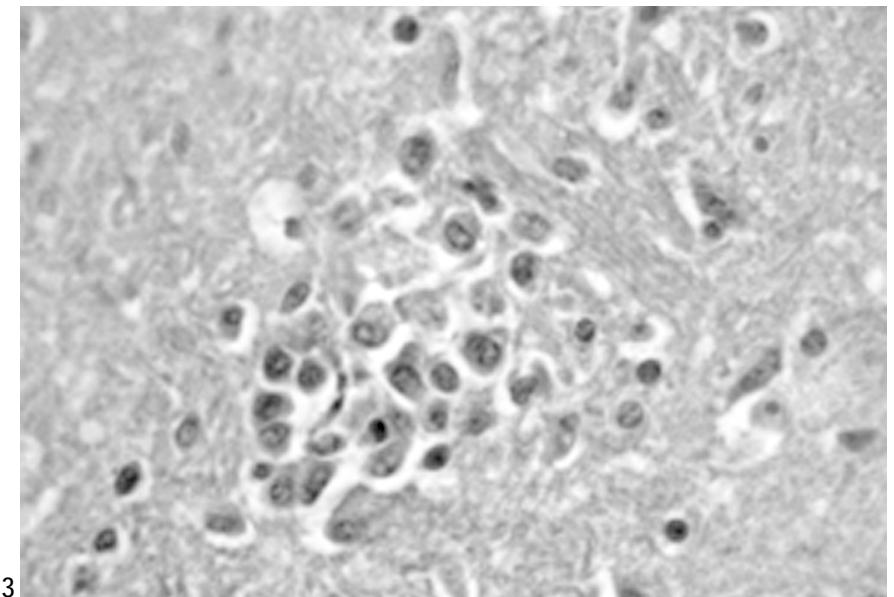

Fig. 1. Malacia acentuada com substituição do neurópilo por células "Gitter" no Tálamo, na meningoencefalite por BHV-5 (Bovino 1.1). HE, obj. 20.

Fig. 3. Malacia discreta com acúmulo focal de céluas "Gitter" no neurópilo, em Colículo rostral, na meningoencefalite por BHV-5 (Bovino 4.1). HE, obj. 40.

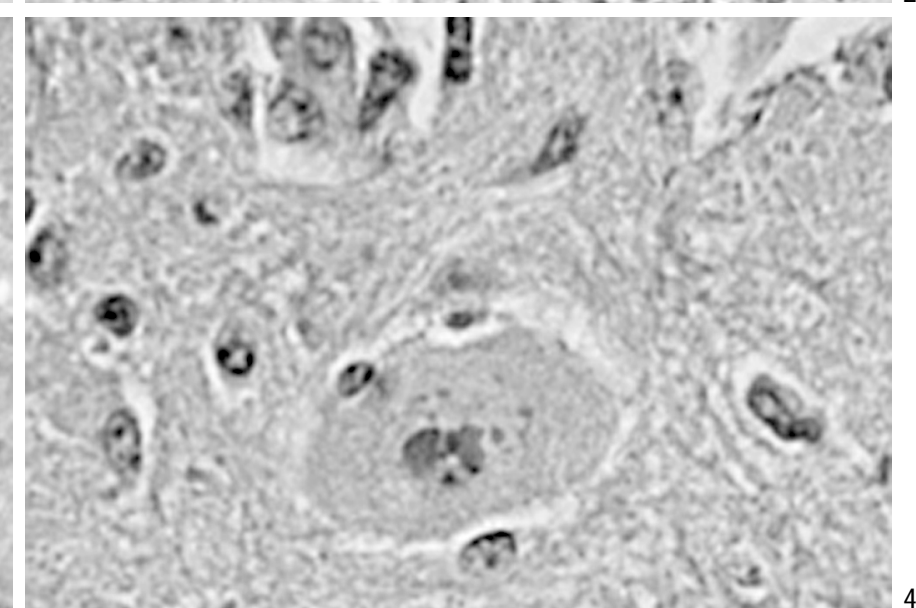

Fig. 2. Malacia moderada com infiltração multifocal de células "Gitter" no neurópilo (setas), aumento dos espaços perivasculares e perineuronais e gliose difusa, em Núcleos de base, na meningoencefalite por BHV-5 (Bovino 7.1). HE, obj. 20.

Fig. 4. Corpúsculo de inclusão intranuclear eosinofílico em neurônio (seta) do Tálamo, com foco de malacia (acima a esquerda), na meningoencefalite por BHV-5 (Bovino 9.1). HE, obj. 40.

\section{Quadro 3. Distribuição e intensidade das lesões inflamatórias nas diferentes secções do SNC avaliadas e} cultivo viral em 10 bovinos com meningoencefalite por BHV-5

\begin{tabular}{|c|c|c|c|c|c|c|c|c|c|c|c|c|c|c|}
\hline \multirow{2}{*}{$\begin{array}{l}\text { Surto }{ }^{a} / \\
\text { Bovino no }\end{array}$} & \multicolumn{4}{|c|}{ Córtex } & \multirow{2}{*}{$\begin{array}{l}\text { Núcleos } \\
\text { da base }\end{array}$} & \multirow{2}{*}{\multicolumn{2}{|c|}{$\begin{array}{l}\text { Cápsula Tálamo } \\
\text { interna }\end{array}$}} & \multirow{2}{*}{$\begin{array}{c}\text { Colículo } \\
\text { rostral }\end{array}$} & \multirow{2}{*}{ Cerebelo } & \multirow{2}{*}{$\begin{array}{l}\text { Pedúnculos } \\
\text { cerebelares }\end{array}$} & \multirow[t]{2}{*}{ Ponte } & \multirow[t]{2}{*}{ Bulbo } & \multirow{2}{*}{$\begin{array}{l}\text { Medula } \\
\text { cervical }\end{array}$} & \multirow{2}{*}{$\begin{array}{c}\text { Cultivo } \\
\text { viral }\end{array}$} \\
\hline & $F$ & $P$ & $T$ & 0 & & & & & & & & & & \\
\hline $1 / 1.1$ & $+t^{c}$ & + & ++ & + & ++ & ++ & +++ & + & - & + & + & + & + & NR \\
\hline $3 / 3.1$ & +++ & $N E$ & +++ & +++ & +++ & +++ & +++ & +++ & + & + & + & $N E$ & $N E$ & $\operatorname{sim}$ \\
\hline $4 / 4.1$ & + & + & $+\mathrm{H}$ & $+\mathrm{H}$ & $++\mathrm{H}$ & $++\mathrm{H}$ & $++\mathrm{H}$ & $++\mathrm{H}$ & ++ & ++ & + & + & + & NR \\
\hline $5 / 5.1$ & + & - & - & - & + & + & + & + & - & - & + & - & - & NR \\
\hline $6 / 6.1$ & + & + & + & + & + & + & + & + & - & - & - & - & + & $\operatorname{sim}$ \\
\hline 7 / 7.1 & +++ & ++ & + & + & $++\mathrm{H}$ & ++ & ++ & + & + & + & + & - & $+\mathrm{H}$ & NR \\
\hline $7 / 7.2$ & ++ & + & + & + & + & + & ++ & $-H$ & $-H$ & $-H$ & + & $N E$ & NE & NR \\
\hline $9 / 9.1$ & ++ & $++\mathrm{H}$ & ++ & $+\mathrm{H}$ & ++ & ++ & ++ & + & + & + & + & ++ & $+\mathrm{H}$ & sim \\
\hline $9 / 9.2$ & ++ & + & + & + & ++ & ++ & ++ & + & - & + & + & + & + & $\operatorname{sim}$ \\
\hline $10 / 10.1$ & +++ & +++ & ++ & ++ & ++ & ++ & ++ & ++ & ++ & ++ & ++ & ++ & + & NR \\
\hline
\end{tabular}

a Nos Surtos 2 e 8 os bovinos apresentaram lesões histológicas características de infecção por BHV-5, entretanto os materiais não estavam disponíveis para o estudo da distribuição dessas lesões. Nestes casos houve cultivo e isolamento viral.

$\mathrm{b}_{\mathrm{F}}=$ córtex frontal, $\mathrm{P}=$ córtex parietal, $\mathrm{T}=$ córtex temporal, $\mathrm{O}=$ córtex occipital, $\mathrm{H}=$ Hemorragia, $\mathrm{NE}=$ não examinado, $\mathrm{NR}=$ não realizado.

$c_{+}$Encefalite discreta com manguitos perivasculares (até 3 camadas de células), focos de gliose, + + encefalite moderada com manguitos perivasculares (de 4 a 7 camadas de células), focos de gliose, +++ encefalite acentuada com manguitos perivasculares (mais de 8 camadas de células), gliose focal e/ou difusa, - ausente. 
do, exceto pela medula cervical do Bovino 2.1; nesse caso as alterações histológicas foram obtidas do Boletim do LRD nํ 14 (Schild et al. 1994) e dos arquivos deste Laboratório. Essas lesões, em ambos os casos, caracterizaram-se por meningoencefalite não-supurativa, evidenciada por acúmulo perivascular de células mononucleares e gliose; áreas de malacia cortiço-cerebral acompanhados por células "Gitter"; meningite e corpúsculos de inclusão em astrócitos.

\section{DISCUSSÃO}

Meningoencefalite por BHV-5 é uma enfermidade freqüente na região sul do Rio Grande do Sul, ocorrendo, principalmente em surtos, com morbidade variável e letalidade alta, embora em alguns casos os animais possam sobreviver. A doença não tem caráter sazonal e nem predileção por raça ou sexo. Dados epidemiológicos semelhantes têm sido observados por outros autores no Rio Grande do Sul, Mato Grosso do Sul, Mato Grosso e Argentina (Riet-Correa et al. 1989, Salvador et al. 1998, Colodel et al. 2002, Perez et al. 2003).

Nos surtos da enfermidade diagnosticados na região sul do Rio Grande do Sul, a taxa de morbidade observada, de 0,76\%a $6,65 \%$ (chegando a 25\%em um surto), é similar ao observado em outras regiões do País, como no Mato Grosso do Sul e Mato Grosso, onde a morbidade pode variar de 0,05\%a 5\%(Salvador et al. 1998, Colodel et al. 2002). Em seis dos surtos estudados, a letalidade foi de $100 \%$ em dois ficou em torno de $75 \%$ e nos outros dois, ao redor de $25 \%$ A taxa de letalidade descrita no Mato Grosso do Sul e Mato Grosso tem sido invariavelmente ao redor de 100\%(Salvador et al. 1998, Colodel et al. 2002). Deve ser considerado, entretanto, que os dados epidemiológicos descritosneste trabalho são pontuais, obtidos em um dado momento de observação de sinais clínicos ou de ocorrência das primeiras mortes; portanto, é possível que um número maior de mortes tenha ocorrido nos dois surtos com letalidade próxima a $25 \%$ sem que isso tenha sido informado pelos proprietários e/ou veterinários. Tem sido relatado em alguns surtos que animais afetados podem se recuperar (Johnston et al. 1962, Gardiner et al. 1964, Riet-Correa et al. 1989). Os bovinos do Surto 3, descrito neste trabalho, que teve letalidade de $77,8 \%$ foram acompanhados até cessarem o aparecimento de casos da doença. Neste surto, 6 animais se recuperaram completamente da enfermidade.

Em todos os surtos deste estudo os bezerros eram criadosa campo, com exceção de um em que os bezerros, após terem sido desmamados, aos 10 meses de idade, estavam confinados, recebendo silagem e sal mineral. Isso tem sido observado também em bovinos no Mato Grosso do Sul onde a doença ocorre, freqüentemente, em bovinos criados extensivamente (Salvador et al. 1998).

A enfermidade afetou animais jovens, de 2 a 24 meses de idade, o que tem sido freqüentemente descrito em diversos surtos observados no Brasil (Riet-Correa et al. 1989, Salvador et al. 1998, Colodel et al. 2002, Gomes et al. 2002) embora, eventualmente, a doença possa afetar animais de até 72 meses (Salvador et al. 1998, Sanches et al. 2000, Colodel et al. 2002, Gomes et al. 2002).
A maioria dos surtos ocorreu após alguma prática de manejo envolvendo os rebanhos afetados; isso confirma o que tem sido demonstrado quanto a patogenia da enfermidade e o estabelecimento de latência do vírus, que é reativado desencadeando a enfermidade quando os bovinos são submetidos a estresse (RietCorrea et al. 1996, Salvador et al. 1998, Halfen \& Vidor 2001, Colodel et al. 2002, Baruel et al. 2003). Em infecções experimentais esta característica do vírus foi comprovada pela administração de corticosteróides sintéticos (Silva et al. 1999, Perez et al. 2002, Vogel et al. 2003). Experimentalmente, foi demonstrado que 0 vírus BHV-5 pode ser reativado por agentes que induzem PEM e, em conseqüência, alguns casos espontâneos de meningoencefalite por BHV-5 poderiam ser secundários às lesões de PEM (David 2002). Essa hipótese decorre da observação de que no Mato Grosso do Sul a PEM e a meningoencefalite por BHV-5 têm características epidemiológicas muito semelhantes (David 2002). No entanto, ao contrário do que ocorre naquele Estado, a PEM é uma enfermidade pouco freqüente na região sul do Rio Grande do Sul.

A doença ocorreu também em bovinos em pastoreio, sem que fosse identificado algum fator de estresse anterior ao aparecimento dos sinais clínicos. Esse fato já havia sido observado em surtos anteriores diagnosticad os pelo LRD (Méndez et al. 1987, Riet-Correa et al. 1989).

Os sinais neurológicos observados nos animais dos diferentes surtos descritos neste trabalho, caracterizados, principalmente, por incoordenação motora, torneio, depressão, sialorréia, cegueira, bruxismo, desidratação e pressão da cabeça contra objetos, ocorreram independentemente da duração do curso clínico da doença. Emagrecimento foi observado apenas nos animais que sobreviveram por mais de 7 dias. Os sinais neurológicos descritos são semelhantes também aos observados por outros autores em casos espontâneos da doença (Ely et al. 1996, Riet-Correa et al. 1996, Salvador et al. 1998, Sanches et al. 2000, Colodel et al. 2002, Gomes et al. 2002, Perez et al. 2003).

Lesões macroscópicas de malacia do córtex cerebral, caracterizadas por áreas amareladas e deprimidas, e hemorragias submeníngeas são freqüentemente descritas em casos espontâneos de encefalite por BHV-5 Johnston et al. 1962, Riet-Correa \& Schild 1995, Riet-Correa et al. 1996, Salvador et al. 1998, Colodel et al. 2002). As lesões macroscópicas no SNC aparentemente não têm relação com o tempo de evolução da doença, uma vez que neste trabal ho, observou-se que as lesões de malacia do córtex cerebral ocorreram tanto nos bovinos que tiveram curso clínico de 2 a 3 dias como naqueles em que a evolução da doença foi superior a 7 dias. No Bovino 1.1 a malacia foi observada, macroscopicamente, também no tálamo e na cápsula interna, o que não tem sido relatado por outros autores, que mencionam a presença dessas lesões apenas no córtex cerebral (Johnston et al. 1962, Riet-Correa \& Schild 1995, Riet-Correa et al. 1996, Salvador et al. 1998, Colodel et al. 2002).

As lesões histológicas observadas nos bovinos deste estudo, caracterizadas por meningoencefalite não-supurativa com presença de manguitos perivasculares de células mononucleares, gliose e malacia da substância cinzenta do córtex cerebral são descritas, também, por outros autores (Barenfus et al. 1963, Hall et al. 1966, Bagust \& Clarck 1972, Riet-Correa et al. 1989, Ely et 
al. 1996, Salvador et al. 1998, Colodel et al. 2002, Perez et al. 2003). Malacia com acentuado acúmulo de células "Gitter" substituindo o neurópilo em extensas áreas, principalmente no córtex cerebral, foi observada em bovinos com evolução clínica superior a 3 dias. Isso também foi observado em trabalho anterior de descrição da doença, no qual os autores sugerem que há relação entre a intensidade dessa lesão e o período de evolução da mesma (Salvador et al. 1998). Nos casos aqui estudados foi observado que no Bovino 3.1, as lesões de malacia com substituição do neurópilo por células gitter foram mais acentuadas do que nos demais bovinos estudados, cuja evolução clínica foi mais prolongada, sugerindo que o tempo de evolução da enfermidade nem sempre é um determinante para a gravidade e extensão destas lesões.

Lesões de malacia estavam presentes no córtex cerebral de todos os bovinos estudados neste trabalho. Isto tem sido observado por diversos autores que estudaram as lesões histológicas na infecção por BHV-5 (Ely et al. 1996, Salvador et al. 1998, Colodel et al. 2002, Perez et al. 2003). Com relação às diferentes regiões do córtex observou-se que, nos casos aqui descritos, existiu uma tendência de as lesões de malacia serem mais graves no córtex frontal, embora to das as regiões tenham sido afetadas. Provavelmente, isto está relacionado com a via de acesso do vírus ao SNC. Foi sugerido em trabalhos experimentais de estudos da patogenia da infecção em coelhos e bovinos, que a via olfatória é a principal via de acesso do vírus ao SNC, embora outras rotas possam ser utilizadas (Beltrão et al. 2000, Meyer et al. 2001, Perez et al. 2002).

Malacia foi observada, também, nos núcleos da base, cápsula interna e tálamo em todos os casos estudados e nos colículos rostrais, ponte, bulbo e medula cervical em alguns casos, demonstrando que essa lesão não está restrita ao córtex cerebral. As lesões dos núcleos da base, cápsula interna e tálamo variavam de moderadas a acentuadas, na maioria do casos, enquanto que as lesões dos colículos, ponte, bulbo e medula cervical foram discretas, caracterizadas por presença de macrófagos espumosos em pequenos nódulos multifocais, distribuídos tanto na substância cinzenta como na substância branca ou áreas caracterizadas pela presença de neurônios retraídos, fortemente eosinofílicos, gliose difusa ou multifocal e aumento dos espaços perivasculares. Lesões extracorticais de localização mais ventral, denominadas lesões profundas de malacia, não têm sido relatadas anteriormente na maioria dos trabalhos que descrevem a histopatologia do SNC de bovinos infectados espontânea ou experimentalmente por BHV-5 (Johnston et al. 1962, Barenfus et al. 1963, Gardiner \& Nairn 1964, Hall et al. 1966, Bagust \& Clarck 1972, Eugster et al. 1974, Diaz et al 1982, Carrillo et al. 1983, Riet-Correa et al. 1989, Weiblen et al. 1989, Ely et al. 1996, Sanches et al. 2000, Colodel et al. 2002, Perez et al. 2002). Salvador et al. (1998), em um estudo de 15 focos de encefalite por BHV-5, no Mato Grosso do Sul, descrevem malacia na cápsula interna, tálamo, tubérculo quadrigêmio, ponte, cerebelo, medula oblonga e médula cervical, caraterizada por múltiplos nódulos gliais nos casos considerados discretos e acúmulos focais de macrófagos nos casos graves. Lesões de malacia nos núcleos da base foram observadas, também, em um estudo retrospectivo realizado na Argentina para estabelecer o diagnóstico de encefalite por BHV-5 em casos em que o diagnóstico presuntivo era de PEM (Perez et al. 2003). As lesões profundas de malacia poderiam ser devidas a caraterísticas diferentes na patogenicidade de cepas de vírus envolvidas nesses surtos; no entanto, não pode ser descartada a possibilidade de que a ocorrência da encefalite por BHV-5 tenha ocorrido secundariamente a lesões prévias de PEM. Foi demonstrado que animais que tinham sido inoculados anteriormente com BHV-5 desenvolviam meningoencefalite após a indução de polioencefalomalacia pela administração de amprólio ou sulfato de sódio (David 2002). Nesses experimentos, um bovino que desenvolveu encefalite após a inoculação do vírus, sem indução de PEM, não apresentou lesões profundas, enquanto que dois dos três animais que desenvolveram, simultaneamente, PEM e meningoencefalite por BHV-5 apresentaram lesões profundas (David 2002). Lesões profundas de malacia, principalmente nos núcleos da base, tálamo e colículos rostral e caudal são observados em casos espontâneos e experimentais de PEM (Tanwar et al. 1993, Low et al. 1996, Loneragan et al. 1998, David 2002)

Discretas áreas de malacia na substância branca cerebelar foram observadas somente no Bovino 4.1. Esta lesão pode ter o corrido devido a anoxia causada por compressão, decorrente do edema, do mesmo modo que ocorre em casos de PEM nos quais é freqüente a ocorrência de edema cerebral e herniação do cerebelo pelo forâmen magno (David 2002). No entanto, no presente estudo, os arquivos do LRD não informaram sobre lesões macroscópicas de edema no SNC, o que sugere que essa lesão se deve à infecção pelo vírus.

Meningoencefalite com manguitos perivasculares de macrófagos e linfócitos foi observada em todos os bovinos estudados neste trabalho, afetando o telencéfalo, o diencéfalo e 0 tronco encefálico com intensidade variada, sendo mais grave nos dois primeiros. Satelitose e neuronofagia foram achados constantes em to dos os cortes avaliados, sendo mais evidentes nos casos em que as lesões inflamatórias e de malacia eram discretas. Em alguns casos, lesões inflamatórias discretas foram observadas na medula cervical. Essas lesões são semelhantes ao que tem sido observado por outros autores (Gardiner \& Nairn 1964, Eugster et al. 1974, Riet-Correa et al. 1989, Ely et al. 1996, Colodel et al. 2002, Perez et al. 2003). Lesões inflamatórias no córtex cerebelar foram observadas em dois dos bovinos deste estudo. Esse é um achado que não tem foi ainda descrito em outros relatos da enfermidade, uma vez que as lesões inflamatórias cerebelares, de modo geral, estão restritas à substância branca.

Corpúsculos de inclusão intranucleares eosinofílicos foram observados no SNC de todos os bovinos deste estudo, localizando-se principalmente em astrócitos. A presença de corpúsculos de inclusão esteve, em todos os casos, associada a áreas de malacia moderada ou discreta, observando-se que não houve relação com o período de evolução da enfermidade e sim com a intensidade da lesão. Corpúsculos de inclusão são freqüentemente relatados em casos espontâneos da enfermidade (RietCorrea et al. 1989, 1996, Salvador et al. 1998, Sanches et al. 2000, Colodel et al. 2002).

0 isolamento viral confirmou o diagnóstico histopatológico em 6 dos casos estudados neste trabal ho. As lesões histológicas 
observadas, associadas à presença de corpúsculos de inclusão intranucleares eosinofílicos, são características da infecção por BHV-5, o que torna possível o diagnóstico, mesmo nos casos em que não há isolamento viral. Alguns autores relatam a ausência de corpúsculos de inclusão em bovinos com meningoencefalite por BHV-5 (Barenfus et al. 1963, Carrillo et al. 1983).

Neste estudo ficou evidenciado que as lesões histológicas causadas pela infecção pelo BHV-5 são difusas, afetando com intensidade variável desde a porção frontal do telencéfalo atéa medula espinhal. Isso explica as diversas manifestações neurológicas observadas nos animais afetados, que vão desde depressão profunda, alternada com perío dos de excitação e cegueira, alterações que caracterizam lesões no diencéfalo e córtex cerebral, incluindo a região occipital, até manifestações como torneio, incoordenação, opistótono e tremores musculares que, em geral, estão associadas a lesões no tronco encefálico, cerebelo e medula cervical (Riet-Correa et al. 2002).

Agradecimentos.- Ao Técnico de Laboratório da UFPel, João Francisco Nunes, pelas preparações histológicas.

\section{REFERÊNCIAS}

Bagust T.J. \& Clark I. 1972. Pathogenesis of meningoencephalitis produced in calves by infectious bovine rhinotracheitis herpesvirus. J. Comp. Pathol. 82:375-382.

Barenfus M., Delliquadri C.A., McIntyre R.W. \& Schroeder R.J. 1963. Isolation of infectious bovine rhinotracheitis virus from calves with meningoencephalitis. J. Am. Vet. Med. Assoc. 143:725-755.

Baruel C., Gomes F. R., Fischer G., Quincoses C., Oliveira L.S., Ferreira L. N. $\&$ Vidor T. 2003. Herpes vírus bovino tipo 1 e 5: caracterização de dois surtos na região sul do estado do Rio Grande do Sul. Anais 23o Congr. Bras. Microbiologia, Florianópolis, SC, Resumo vi 010/Seção Virologia.

Beltrão N., Flores E.F., Weiblen R., Silva A.M., Roehe P.M. \& Irigoyen L.F. 2000. Acute infection and neurological discease by bovine herpesvirus type-5 (BHV-5): rabbits as an experimental model. Pesq. Vet. Bras. 20(4): 144-150.

Carrillo B.J., Pospischil A. \& Dahme E. 1983. Pathology of a bovine viral necrotizing encephalitis in Argentina. Zbl. Vet. Med. A 30:161-168.

Colodel E.M., Loretti A.P., Cruz C.E.F. \& Driemeier D. 1998. Polioencefalomalacia em caprinos associada à ingestão de Hovenia dulcis (Uva do Japão). Boletim no 18 do Laboratório Regional de Diagnóstico, Editora Universitária, Pelotas, p.35-42.

Colodel M.E., Nakazato L., Weiblen R., Mello R.M., Silva R.P., Souza M.A., Oliveira J.A. \& Caron L. 2002. Meningoencefalite necrosante em bovinos causada por herpesvírus bovino no estado de Mato Grosso, Brasil. Ciência Rural, Santa Maria, 32(2):293-298.

D'Arce R.C.F., Almeida R.S., Silva T.C., Franco A.C., Spilki F., Roehe P.M. \& Arns C.W. 2002. Restriction endonuclease and monoclonal antibody analysis of Brazilian isolates of bovine herpesvirus types 1 and 5. Vet. Microbiol. 88:315-324.

David N. 2002. Associação de meningoencefalite por herpesvírus bovino5 com polioencefalomalacia. Dissertação de Mestrado, Faculdade de Veterinária, UFPel, Pelotas, RS. 55 p.

Dias L.E., Maisonnave J., Guarino H., Paullier C., Perdomo E., Figares A. \& Izaguirre R. 1982. Rinotraqueitis Infecciosa Bovina (IBR), descripción de un cuadro clínico en terneros de tambo. Anais III Congr. Nac. Veterinaria, Montevideo, p. 521-527.

D'Offay J.M., Mock R.E. \& Fulton R.W. 1993. Isolation and characterization of encephalitic bovine herpesvirus type 1 isolates from cattle in North America. Am. J. Vet. Res. 54(4):534-538.

Ely R.W., D'offay J.M., Ruefer A.H. \& Cash C. 1996. Bovine herpesviral encephalitis: a retrospective study on archived formalin-fixed, paraffinembedded brain tissue. J. Vet. Diagn. Invest. 8:487-492.

Eugster A.K., Angulo A.B. \& Jones L.P. 1974. Herpesvirus encephalitis in range calves. Proc. Annu. Meet. Assoc. Vet. Lab. Diag. 17:267-281.

Gardiner M.R. \& Nairn M.E. 1964. Viral meningoencephalitis of calves in western Australia. Aust. Vet. J. 40:225-228.

Gomes L.I., Rocha M.A., Costa E. A., Lobato Z. I. P., Mendes L.C.N., Borges A.S., Leite R.C. \& Barbosa-Stancioli E.F. 2002. Detecção de herpesvírus bovino 5 (BHV-5) em bovinos do sudeste brasileiro. Arq. Bras. Med. Vet. Zootec. 54(2):217-220.

Halfen D.C. \& Vidor T. 2001. Meningoencefalite por hepesvírus tipo 5, p. 97-108. In: Riet-Correa F., Schild A. L., Méndez M. C. \& Lemos R. A. A.(ed.) Doenças de Ruminantes e Eqüinos. Vol. 1. 2ª ed. Editora Varela, São Paulo, SP.

Hall W.T.K., Simmons G.C., French E.L., Snowdon W.A. \& Asdell M. 1966. The pathogenesis of encephalitis caused by the infectious bovine rhinotracheitis virus. Aust. Vet. J. 42:229-237.

Hübner S.O., Riet-Correa F., Costa P.B., Lemos R.A. \& Rodrigues I.C. 1999. Relationship between poliencephalomalacia and encephalitis by bovine herpesvirus-5 in cattle. In: Anais IX Encontro Nacional de Patologia Veterinária, Belo Horizonte, MG, p.85. (Resumo)

Johnston L.A.Y., Simmons G. C. \& McGavin M. D. 1962. A viral meningoencephalitis in calves. Aust. Vet. J. 38:207-215.

Lemos R.A.A. \& Nakazato, L. 2001. Polioencefalomalacia, p. 547-553. In: Riet-Correa F., Schild A. L., Méndez M. C. \& Lemos R. A. A. (ed.) Doenças de Ruminantes e Eqüinos. Vol. 2. 2를 ed. Varela, São Paulo, SP.

Loneragan G.H., Gould D.H., Callan R.J., Sigurdson C.J. \& Hamar D.W. 1998. Association of excess sulfur intake and an increase in hidrogen sulfide concentrations in the ruminal gas cap of recently weaned beef calves with polioencephalomalacia. J. Am. Vet. Med. Assoc. 213(11): 1599-1604.

Low J.C., Scott P.R., Howie E., Lewis M., Fitzsimons J. \& Spence J.A. 1996. Sulphur-induced polioencephalomalacia in lambs. Vet. Rec. 138:327329.

Nakazato L., Lemos R. \& Riet-Correa F. 2000. Polioencefalomalacia em bovinos nos estados de Mato Grosso do Sul e São Paulo. Pesq. Vet. Bras. 20:119-125.

Meyer G., Lemaire M., Ros C., Belak K., Gabriel A., Cassart D., Coignoul F., Belak S. \& Thiry E. 2001. Comparative pathogenesis of acute and latent infections of calves with bovine herpesvirus type 1 and 5 . Arch. Virol. 146:633-652.

Méndez M. C., Riet-Correa F., Schild A. L. \& Ferreira J. L. M. 1986. Doenças diagnosticadas no ano de 1986. Boletim do Laboratório Regional de Diagnóstico. Editora Universitária, Pelotas, p.30.

Perez S. E., Bretschneider M. R., Leunda M. R., Osorio F. A., Flores E. F. \& Odeón A. C. 2002. Primary infection, latency, and reactivation of bovine herpesvirus type 5 in the bovine nervous system. Vet. Pathol. 39:437444.

Perez S. E., Vagnozzi A., Sur J. H., Odriozola E., Campero C. M. \& Odeón A. C. 2003. Análisis retrospectivo de casos con diagnóstico de necrosis cerebrocortical y su relación com herpesvirus bovino tipo 5 . Revta Argent. Microbiol. 35:69-73.

Riet-Correa F., Schild A. L., Méndez M. C., Oliveira J. A., Gil-Turnes C. \& Gonçalves A. 1983. Atividades do Laboratório Regional de Diagnóstico e Doenças da Área de Influência no Período 1978-1982. Editora Universitária, Pelotas, Pelotas, RS. 97p.

Riet-Correa F., Vidor T., Schild A.L. \& Méndez M.C. 1989. Meningoencefalite e necrose do córtex cerebral em bovinos causada por herpesvirus bovino-1. Pesq.Vet. Bras. 9:13-16.

Riet-Correa F. \& Schild A.L. 1995. Doenças diagnosticadas pelo Laboratório Regional de Diagnóstico no ano de 1994 e comentários sobre algumas doenças. Boletim no. 15, Laboratório Regional de Diagnósticos. Editora Universitária, Pelotas, p.7-9. 
Riet-Correa F., Moojen V., Roehe P.M. \& Weiblen R. 1996. Viroses confundíveis com febre aftosa: revisão bibliográfica. Ciência Rural, Santa Maria, 26: 323-332.

Riet-Correa F., Riet-Correa G. \& Schild A.L. 2002. Importância do exame clínico para o diagnóstico das enfermidades do sistema nervoso em ruminantes e equídeos. Pesq. Vet. Bras. 22(4):161-168.

Salvador S.C., Lemos R.A.A., Riet-Correa F., Roehe P.M. \& Osório A.L.A.R. 1998. Meningoencefalite em bovinos causada por herpesvirus bovino 5 no Mato Grosso do Sul e São Paulo. Pesq.Vet. Bras. 18:76-83.

Sanches A. W. D., Langohr I. M., Stigger A. L. \& Barros C. S. L. 2000. Doenças do sistema nervoso central em bovinos no Sul do Brasil. Pesq.Vet. Bras. 20(3):113-118.

Santos, M. N., Jardim Filho J. O. \& Grando F. A. 1983. Polioencefalomalacia em bovinos no Rio Grande do Sul. Pesq. Vet. Bras. 3:37-39.

Schild A. L., Riet-Correa F., Pereira D. B., Ladeira R. \& Raffi M. 1994. Doenças diagnosticadas pelo Laboratório Regional de Diagnósticos em
1993. Boletim oㅡ 14, Laboratório Regional de Diagnóstico. Editora Universitária, Pelotas, p.23-26.

Summers B.A., Cummings J.F. \& De Lahunta A. 1995. Veterinary Neuropathology. Mosby, London, p.527.

Tanwar R.K., Malik K.S. \& Sadana J.R. 1993. Polioencephalomalacia induced with amprolio in buffalo calves: pathologic changes of the central nervous system. J. Vet. Med. 40:58-66.

Vogel F.S., Caron L., Flores E.F., Weiblen R., Winkelmann E.R., Mayer S.V. \& Bastos R.G. 2003. Distribution of bovine herpesvirus type 5 DNA in the central nervous system of latently, experimentally infected calves. J. Clin. Microbiol. 41(10):4512-4520.

Weiblen R., Barros C. S. L., Canabarro T. F. \& Flores I.E. 1989. Bovine meningoencephalitis from IBR virus. Vet. Rec. 124(25):666-667.

Weiblen R., Moraes M.P., Rebelatto M.C., Lovato T.L. \& Canabarro T.F. 1996. Bovine herpesvirus isolates. Revta Microbiol., São Paulo, 27:208211. 